The medical officers' scores on the clinical examination ranged from $7-13$. The mean \pm s.d. posttraining score was $11.2 \pm 1.6$. Twenty-six $(68 \%)$ of the doctors scored above $75 \%$. When this group was compared with the remaining 12 doctors, no significant differences emerged. Qualitative evaluation of the responses revealed that, out of 456 possible responses, there were no major errors and $16(35 \%)$ minor errors. In another 22 instances $(4.8 \%)$ no answers were written. These response categories mainly included management of side effects, nonpharmacological aspects of management, duration of treatment and the specific advice that was to be provided about illness and treatment. The most commonly noticed error was an inability to distinguish between anxiety neurosis and depressive neurosis.

\section{Comment}

Clinical examination as a method of assessment would seem to have face value as the most appropriate method of assessing clinical skills. However certain of the limitations of clinical examination have to be overcome to make it more valid. The first problem is the frequently observed heterogeneity of patient characteristics. Patients often differ with respect to their manifest symptomatology, cooperativeness, and ability to convey the required information in the most appropriate manner to arrive at a diagnosis. Since these are likely to influence trainees' performance, it is necessary for the assessor to ensure adequate homogeneity of the patients. This was ensured in the present investigation by prior screening of patients. The second problem pertains to the rating of trainees' performance in an objective manner. To ensure this, a structured response sheet was used.

The results of the present investigation suggest that primary care physicians can effectively recognise and manage mental health problems. Clinical errors are infrequent and are of a minor nature. However, it is not implied that more serious errors would never occur in the doctors' practice since there will often be difficult clinical situations. The doctors might refer such problems to a specialist. Alternatively they might carefully monitor the patient's progress and revise the diagnosis and treatment. Finally there is the remote possibility that a major error would go unrecognised. This highlights the need for an evaluation of the doctors' diagnostic and therapeutic practices during their actual practice following training.

\section{References}

National Mental Health Programme for India (1982) Directorate General of Health Services, New Delhi.

Progress Report (1988) National Institute of Mental Health and Neurosciences, Bangalore, India.

Sriram, T. G., Chandrashekar, C. R., Sundar Moily, Kishore Kumar, K. V., Raghuram, A., IsaAC, M. K. \& SRINIVASA MURTHY, R. Standardisation of multiplechoice questionnaire for evaluating medical officers' training in psychiatry. Social Psychiatry and Psychiatric Epidemiology (in press).

, - ISAAC, M. K., SRINIVASA MURTHY, R., Kishore Kumar, K. V., Molly, S. \& Shanmugham, V. Development of case vignettes to assess primary care medical officers' training in mental health (submitted for publication).

Wilkinson, G. (1985) Mental Health Practices in Primary Care Settings: an annotated bibliography 1977-85. London: Tavistock.

\title{
Extending management training for senior registrars
}

\author{
ElaINE M. GADD, Senior Registrar (Honorary Lecturer) in Psychiatry, Hollymoor \\ Hospital, Tessall Lane, Northfield, Birmingham B31 5EX
}

It is recognised that the consultants of the future will have a greater management role than those of the past. The Griffiths report (1983) regarded doctors as 'natural managers', although this has been challenged by some authors. They suggest that medical training, with its emphasis on the individual case and rapid 
decision-making (Higgins, 1989), leads to a very different perspective from the manager considering the often competing long-term needs of many individuals.

It was recognised by Griffiths himself that management should be an integral part of training. The NHS Training Authority (1986) suggested that management training may be divided into three areas:

(a) helping doctors to practice their clinical skills more effectively

(b) increasing the effectiveness of doctors' contributions to management decisions

(c) enabling clinicians to manage their department or service more effectively.

It was subsequently suggested (NHS Training Authority, 1989) that although the first area should be taught locally from the earliest years of training (e.g. by audit, cost awareness), the latter areas should be taught after completion of postgraduate examinations. It was recommended that such training should consist of involvement with local management, supplemented by selected formal courses. Ideally, both personnel and resource management issues will be covered. Personnel management includes skills such as leadership, team-building and motivation, the management of conflict and effective recruitment (NHS Training Authority, 1986). Resource management may include training in budget holding and information technology.

A variety of courses have been developed for senior registrars, both at regional and national level, e.g. by the Kings Fund. Such courses are normally short, lasting a week or less. More advanced courses are offered, usually leading to a management qualification (either from the Institute of Health Services Management or the degree of MBA) and lasting several years. At present few intermediate options are available, although the Welsh model (Smith, G. J. et al, 1986) merits further consideration. A planned programme of management development takes place over three years; after 15 half-day visits to relevant departments and units in the first year, the trainees attend a one-week residential management course in their second year, followed by a more advanced course a year later. At this time, teaching in management skills, including effective chairmanship and committee skills, takes place. However, the general lack of such courses would appear to mean that senior registrars' management skills are unlikely to be maximised.

It is recognised that courses must be supplemented by involvement in local management. For most trainees, this will consist of attendance at Medical Staff Committees and Divisions. Some trainees may also have the opportunity to attend planning meetings, particularly in specialities dealing with longterm care, e.g. psychogeriatrics and rehabilitation.
Apart from such meetings, trainees have limited contact with managers.

Having attended a short management course and had experience of local medical advisory committees, I wished to extend my management experience. The NHS Training Authority (1986) suggested the use of management 'apprenticeships' and I therefore arranged an experimental one-week attachment with a local Unit General Manager (UGM). I received a high degree of co-operation, both from the UGM and from the District Health Authority managers, which enabled me to observe the complete workload of that week. During the 48 hour week worked (range: $8.75-10.6$ hours/day), the time spent in various activities was noted.

The proportion of time (shown in brackets) a UGM devotes to activities varies from week to week, and one week was insufficient to observe all the activities undertaken. In the week's attachment, half the time was divided between dealing with correspondence $(24 \%)$ and meetings at the District Health Authority (23\%). These meetings covered budget setting, personnel management, service planning and evaluation of staff development courses, and were supplemented by interviews with individual district officers $(6 \%)$. Time spent in the local unit was divided between meetings with managers, of broadly similar content to those at the District Health Authority, but focused on local issues (14\%) and interviews with individual staff (18\%). Unit General Managers from the region met to discuss the White Paper (4\%); the remainder of the time was spent in travel $(8 \%)$ and lunch $(3 \%)$.

During the week, it became clear that doctors' individual relationships with patients, and their commitment to their welfare, is reflected in their behaviour in medical advisory machinery meetings. The managers of the District Health Authority were more able to view issues dispassionately. Their committee skills, coupled with effective chairmanship, enabled their meetings to be more productive in terms of material covered and decisions reached than medical advisory meetings often appear to be.

The management attachment allowed local issues to be examined from a variety of perspectives. Observation of the functions and organisation of District Health Authority managers enabled deeper understanding of material presented in theoretical management courses. The extent of local training courses available to managers, but not widely advertised to doctors, e.g. in leadership and team motivation, revealed the potential for further extension of management training.

It was also clear that the knowledge base of a manager is in many ways as broad as that of a doctor. However, the areas of expertise of doctors and managers seldom overlap, which results in potential for mutual underestimation. 
The management role of consultants is continually increasing; if they are to make effective contributions to management decisions and management of services, it is essential that they are adequately prepared. Management training should not be an optional, but an 'integral part of training' (Smith et al, 1986). There is a need both for theoretical management education throughout higher training (as in the Welsh model), and for practical management experience. A short attachment to a Unit General Manager would be a useful addition to every senior registrar's training programme.

\section{Acknowledgement}

I would like to thank Dr T. Harrison for his helpful comments on an earlier draft of the paper.

\section{References}

GRIFFITS, R. (1983) NHS Management Inquiry Report. London: DHSS.

HigGINS, J. (1989) Management training in psychiatric practice. Psychiatric Bulletin, 13, 456-460.

National Health Service Training Authority (1986) Developing the Role of Doctors in the Management of the NHS. Bristol: NHSTA.

- (1989) Doctors and Management and Development: Policy Proposals from the NHS Training Authority. Bristol: NHSTA.

Smith, G. J., Makinson, D. H. \& Farrow, S. C. (1986) Learning to swim with the Griffiths tide. British Medical Journal, 292, 150-151.

\title{
Trainees' forum
}

\section{Career progression in psychiatry: perceptions and realities}

\author{
Ola Junaid, Registrar in Psychiatry; and Jill Staines, Locum Senior Registrar in \\ Psychiatry, University of Nottingham Medical School
}

The guidelines on criteria necessary for promotion to senior registrar grade in psychiatry may be found in The Handbook for Inceptors and Trainees 1987. The criteria are essentially those in the 1980 edition, namely the need for possession of MRCPsych status and completion of at least three years general professional training approved by the College. Yet it is undeniable that in recent years eligible candidates have experienced much more difficulty in achieving appointment as a senior registrar. Indeed Holden (1988) comments that "dedicated clinical service and the qualification of MRCPsych is insufficient to guarantee a registrar success in his or her application for a senior registrar post". In the increasingly competitive job market research experience, possession of publications, and management training have become valuable assets for prospective candidates. Our concern at the lack of pertinent career guidance for trainee psychiatrists prompted us to look at trainees' perceptions of requirements and at the provisions which exist in their training to enhance their career prospects. 